\title{
Prognosis of small bowel adenocarcinoma treated with Mayo or Xelox regimen: A matched case-control study from a database of 581 patients with colorectal cancer
}

\author{
JACOB THOMSEN LØNBORG, ADAM VILMAR, DAVID MÅRD, \\ SØREN ASTRUP JENSEN and JENS BENN SØRENSEN \\ Department of Oncology 5073, Finsen Centre, Rigshospitalet, University \\ of Copenhagen, Blegdamsvej 9, DK-2100 Copenhagen, Denmark
}

Received April 10, 2007; Accepted June 28, 2007

\begin{abstract}
The purpose of this study was to compare the effects of chemotherapy on the prognosis for patients with adenocarcinoma of the small bowel (SBC) and colorectal cancer (CRC). A case-control study was conducted, comprised of 13 SBC cases treated palliatively $(n=7)$ following surgery with capecitabine monotherapy (Xeloda) combined with oxaliplatin (Xelox), or with adjuvant 5-fluorouracil chemotherapy (Mayo) $(n=6)$. The control group was selected from a database of 581 patients with CRC, with each SBC case being matched to $5 \mathrm{CRC}$ controls. In the palliative group, response rates (RR) for SBC patients were 14\%, compared to $35 \%$ for CRC patients $(\mathrm{p}=0.08)$. Median progression-free survival (PFS) times were 4 and 6 months $(\mathrm{p}=0.8)$ and median overall survival (OS) times were 8.4 and 16.4 months $(\mathrm{p}=0.9)$ for SBC and CRC patients, respectively. In the adjuvant group, the recurrence-free survival rates were 66 and $89 \%(\mathrm{p}=0.6)$ after 1 year and 66 and $71 \%(\mathrm{p}=0.7)$ after 3 years. Three-year overall survival rates were 80 and $80 \%(\mathrm{p}=0.3)$ in the palliative group, and 80 and $66 \%(p=0.4)$ in the adjuvant group. Standard chemotherapy regimes seemed less effective on SBC than on CRC patients, and had a less favorable prognosis. However, reliable conclusions cannot be drawn from a small patient population, and multicentre studies are needed.
\end{abstract}

\section{Introduction}

Adenocarcinoma of the small bowel (SBC) is very rare, with only 6,000 cases reported annually in the USA (www.cancer. gov). In contrast, cancer of the gastrointestinal tract is diagnosed in around 250,000 patients a year. In approximately

Correspondence to: Dr Jacob Thomsen Lønborg, Department of Oncology 5073, Finsen Centre, Rigshospitalet, University of Copenhagen, Blegdamsvej 9, DK-2100 Copenhagen, Denmark

E-mail: jacoblonborg@mail.dk

Key words: small bowel, adenocarcinoma, chemotherapy, casecontrol study
150,000 of those cases, it is located in the colon or rectum and is diagnosed as colorectal cancer (CRC) (www. cancer. gov).

SBCs are most frequently located in the duodenum, then in the jejunum and ileum. The most common type is adenocarcinoma, but carcinoids and lymphomas also occur. The late appearance of symptoms, the sporadic pattern of the disease and the low incidence of SBC may further delay the start of therapy. It has been reported that the time from the first appearance of symptoms to diagnosis is $12-33$ months (1). This may explain why only $40-65 \%$ of patients with SBC are candidates for curative resection (2), whereas $70-80 \%$ of CRC patients are, at the time of diagnosis, eligible for it (3). Statistics show that the prognosis for SBC is worse than it is for CRC. Howe et al (4) looked at the American National Cancer Database from 1985 to 1995 and found, in total, 4,995 patients with different stages of SBC. The 5-year overall survival (OS) rate of those patients was only approximately 30\% (4), whereas the SEER report found that, between 1990 and 1992, the 5-year OS rate of patients with all stages of CRC in the USA was $62 \%$ (www.cancer.gov).

No specific chemotherapy regimens are associated with SBC. It is usually treated according to the same principles as $\mathrm{CRC}$, mainly because the two share some molecular features, but also because both neoplasms tend to arise from pre-existing adenomatous polyps. Moreover, both have a well-established comorbidity with inflammatory bowel disease (5). Results from studies investigating chemotherapy treatments for SBC are mixed, though palliative chemotherapy has been explored and described more thoroughly than adjuvant chemotherapy. Five studies of palliative chemotherapy evaluated 8-14 month OS times, and reported response rates (RR) of 7-37\% (6-10).

In order to aid in the prognosis of 5-FU-based palliative and adjuvant SBC chemotherapy treatments, a retrospective case-control study was designed in both palliative and adjuvant settings. The results were compared to those of CRC patients, obtained from a database of 581, with each SBC case being matched to $5 \mathrm{CRC}$ controls.

\section{Patients and methods}

Patients. SBC and CRC patients were consecutively treated at the Department of Oncology, Rigshospitalet, Copenhagen, Denmark, from 1993 to 2003. Information on patients and 
Table I. Characteristics for patients with small bowel (cases) and colorectal (controls) adenocarcinoma treated with palliative chemotherapy.

\begin{tabular}{|c|c|c|}
\hline & $\begin{array}{c}\text { Cases (small } \\
\text { bowel) } n=7\end{array}$ & $\begin{array}{l}\text { Controls (colon, } \\
\text { rectum) } n=35\end{array}$ \\
\hline \multicolumn{3}{|l|}{ Gender } \\
\hline Male & 3 & 15 \\
\hline Female & 4 & 20 \\
\hline \multicolumn{3}{|l|}{ Age (years) } \\
\hline Median (range) & $56(38-67)$ & $59(43-74)$ \\
\hline \multicolumn{3}{|l|}{ Metastasis } \\
\hline No & 1 & 5 \\
\hline Yes & 6 & 30 \\
\hline $\mathrm{NE}$ & 0 & 0 \\
\hline \multicolumn{3}{|l|}{ PS baseline } \\
\hline $0-1$ & 7 & 28 \\
\hline 2 & 0 & 3 \\
\hline $\mathrm{NE}$ & 0 & 4 \\
\hline \multicolumn{3}{|l|}{ LDH baseline } \\
\hline Normal & 4 & 8 \\
\hline $1-2.5 \times$ upper limit & 3 & 23 \\
\hline$>2.5 \mathrm{x}$ upper limit & 0 & 2 \\
\hline $\mathrm{NE}$ & 0 & 2 \\
\hline \multicolumn{3}{|l|}{ Regimens } \\
\hline 5-FU (Mayo) & 1 & 0 \\
\hline Capecitabine & 1 & 12 \\
\hline Xelox & 5 & 23 \\
\hline
\end{tabular}

NE, not evaluable; PS, performance status (range 0-2); LDH, lactic dehydrogenase; upper limit for LDH is 205 units/1; 5-FU, 5-FU $425 \mathrm{mg} / \mathrm{m}^{2}$ in 5 days with leucovorin $20 \mathrm{mg} / \mathrm{m}^{2}$ every 4 th week (Mayo regimen); Capecitabine, $1250 \mathrm{mg} / \mathrm{m}^{2}$ bid for 2 weeks every 3 weeks; Xelox, capecitabine $1250 \mathrm{mg} / \mathrm{m}^{2}$ bid for 2 weeks every 3 weeks in combination with oxaliplatin $130 \mathrm{mg} / \mathrm{m}^{2}$ on day 1 .

tumor-specific characteristics were obtained from oncological, surgical and pathological records. Patients needed to have had a biopsy-proven diagnosis of SBC (including the appendix) to qualify as case, or CRC to qualify as a control. Pathological characteristics of tumor staging and grading were obtained for all patients. Controls were selected from a database of 581 consecutive CRC patients $(11,12)$. OS times were updated in December of 2005.

Matching criteria. Five controls were matched completely to each case according to the following criteria: gender, the pathological characteristics of tumor stage and grade, and the chemotherapy regimen followed. Furthermore, an attempt was made to match cases and controls according to age, baseline performance status (PS) and baseline levels of plasma lactate dehydrogenase $(\mathrm{LDH})$ concentration. Tumor stage and grade
Table II. Characteristics for patients with small bowel (cases) and colorectal (controls) adenocarcinoma treated with adjuvant chemotherapy.

\begin{tabular}{|c|c|c|}
\hline & $\begin{array}{l}\text { Cases (small } \\
\text { bowel) } n=6\end{array}$ & $\begin{array}{l}\text { Controls (colon, } \\
\text { rectum) } n=30\end{array}$ \\
\hline \multicolumn{3}{|l|}{ Gender } \\
\hline Male & 3 & 15 \\
\hline Female & 3 & 15 \\
\hline \multicolumn{3}{|l|}{ Age (years) } \\
\hline Median (range) & $55(42-75)$ & $54(40-79)$ \\
\hline \multicolumn{3}{|l|}{ Dukes } \\
\hline $\mathrm{B}$ & 1 & 5 \\
\hline $\mathrm{C}$ & 5 & 25 \\
\hline \multicolumn{3}{|l|}{ TNM stage } \\
\hline \multicolumn{3}{|l|}{ T-stage } \\
\hline$\leq 3$ & 2 & 7 \\
\hline 4 & 4 & 23 \\
\hline \multicolumn{3}{|l|}{$\mathrm{N}$-stage } \\
\hline $0-1$ & 6 & 16 \\
\hline$\leq 2$ & 0 & 14 \\
\hline \multicolumn{3}{|l|}{ M-stage } \\
\hline 0 & 6 & 30 \\
\hline 1 & 0 & 0 \\
\hline \multicolumn{3}{|l|}{ PS baseline } \\
\hline $0-1$ & 6 & 30 \\
\hline 2 & 0 & 0 \\
\hline \multicolumn{3}{|l|}{ LDH baseline } \\
\hline Normal & 1 & 0 \\
\hline $1-2.5 \mathrm{x}$ upper limit & 4 & 27 \\
\hline$>2.5 \mathrm{x}$ upper limit & 1 & 3 \\
\hline \multicolumn{3}{|l|}{ Regimen } \\
\hline 5-FU (Mayo) & 6 & 30 \\
\hline
\end{tabular}

PS, performance status; LDH, lactic dehydrogenase; upper limit for LDH is 205 units $/$; 5 -FU, 5 -FU $425 \mathrm{mg} / \mathrm{m}^{2}$ in 5 days with leucovorin $20 \mathrm{mg} / \mathrm{m}^{2}$ every 4 th week (Mayo regimen).

were assessed according to Dukes' classification. Baseline values of the Eastern Cooperative Oncology Group (ECOG) PS were used. Three categories were developed in order to match patients according to LDH values (normal/1-2.5 x upper limit/>2.5 x upper limit). Chemotherapy regimens were applied according to the standard guidelines of the department. The guidelines were changed during the inclusion period from capecitabine $1,250 \mathrm{mg} / \mathrm{m}^{2}$ bid for 2 weeks every 3 weeks as monotherapy (Xeloda), to a combination with oxaliplatin $130 \mathrm{mg} / \mathrm{m}^{2}$ on day 1 (Xelox) as a palliative regimen. The adjuvant regimen consisted of a bolus IV injection of 5-FU $425 \mathrm{mg} / \mathrm{m}^{2}$ for 5 days with leucovorin $20 \mathrm{mg} / \mathrm{m}^{2}$ every 4 th week for 6 courses (Mayo). 
Toxicity. Toxicity, blood counts, blood chemistry, body weight and ECOG PS were assessed at baseline after each chemotherapy course. Toxicity was evaluated according to Common Toxicity Criteria (CTC). Electrocardiography was performed before chemotherapy and when indicated by the symptoms. The worst toxicity grade of each patient was noted. Severe toxicity was defined as grades 3 and 4 . In those cases, treatment dosage was reduced or treatment was stopped, with the exception of alopecia. Dose reductions were evaluated as being 75 and $50 \%$ of the standard baseline dose. The number of treatment courses received were divided into the following groups $\leq 3,4-6,7-9$ and 10-12.

Evaluation of disease status, effect and statistical methods. The impact of treatment was measured by RR, OS time and progression-free survival (PFS) time. Disease status was evaluated after 3 courses, unless clinical symptoms indicated disease progression, and was assessed as bidimensional measurements of tumor lesions. RR included partial and complete response. Partial response was defined as a $\geq 50 \%$ reduction of tumor mass, and complete response as a complete absence of detectable tumor mass. Progression was defined as a $\geq 25 \%$ increase in tumor mass or clinical progression. Differences in RRs were evaluated using the Mann-Whitney $\mathrm{U}$ test. OS and PFS times were defined as the duration from the start of chemotherapy until death or progression, respectively, and were estimated according to the Kaplan-Meier method. The log-rank test was used to identify statistical differences between curves and the actual size of differences as a hazard ratio (HR) with a $95 \%$ confidence interval (CI). OS and PFS in the adjuvant group and for all patients were analyzed as 1-, 3- and 5-year OS/PFS rates and were comared using Fischer's exact test. Prognostic predictors such as baseline PS, baseline LDH, gender, age, and tumor stage were analyzed independently of PFS and OS using a multivariate analysis (Cox). Differences in the reduction of treatment doses, number of treatment courses, worst PS and weight change were calculated using the Mann-Whitney U test. Worst toxicity was evaluated using the $\chi^{2}$ test. P-values of $\leq 0.05$ were considered to be significant.

\section{Results}

Patient characteristics. A total of 13 SBC patients were treated during the inclusion period. Patient characteristics in the palliative and the adjuvant groups are summarized in Tables I and II, respectively. In the palliative group there were 7 cases, 6 of which had a primary SBC location in duodenum and 1 in the appendix. In the control group there were 35 patients, 8 of which had a primary location site in the rectum and 27 in the colon. Cases were between the ages of 38-67 (median 56 years) and controls 43-74 (median 59 years). LDH baseline levels were elevated in $3 / 7$ (43\%) of cases vs. $25 / 33(76 \%)$ of controls (2 patients were not evaluated). The PS baseline was 2 in 0/7 (0\%) vs. 3/35 (9\%), and M stage 1 was reported in $6 / 7(86 \%)$ vs. $30 / 35(86 \%)$ of cases and controls, respectively. One SBC patient treated using the Mayo regimen was matched with 5 CRC patients treated with capecitabine. In the adjuvant group, there were 6 cases and 30 controls. Within the cases, 2 patients had primary cancer locations in the appendix, 2 in the jejunum and 2 were not
Table III. Response rates, tolerable dose as percent of standard dose and number of treatment courses for patients with small bowel and colorectal adenocarcinoma treated with palliative chemotherapy.

\begin{tabular}{lrrrrr}
\hline & $\begin{array}{c}\text { Small bowel } \\
(\mathrm{n}=7) \\
\text { No. }(\%)\end{array}$ & $\begin{array}{c}\text { Colorectal } \\
(\mathrm{n}=35) \\
\text { No. }(\%)\end{array}$ & P-value \\
\hline $\begin{array}{l}\text { Best response } \\
\text { Complete response }\end{array}$ & 0 & $(0)$ & 3 & $(9)$ & 0.08 \\
Partial response & 1 & $(14)$ & 9 & $(26)$ & \\
No change & 2 & $(29)$ & 12 & $(34)$ & \\
Progression disease & 3 & $(43)$ & 8 & $(23)$ & \\
Not evaluated & 1 & $(14)$ & 3 & $(9)$ & \\
\hline
\end{tabular}

evaluated. Among the controls, all were located in the colon and none in the rectum. Cases were between the ages of 4275 (median 55 years) and controls 40-79 (median 54 years). $\mathrm{T}$ stage 4 was observed in $4 / 6(67 \%)$ vs. $23 / 30(77 \%), \mathrm{N}$ stage 2 was observed in $0 / 6$ vs. 14/30 (47\%) and LDH baseline levels were elevated in 5/6 (83\%) vs. 30/30 (100\%), respectively. Otherwise no statistically significant (ns) differences were observed.

Response evaluation and survival times. RRs in the palliative treatment group are shown in Table III. RRs were 14\% for patients with SBC and 35\% ( $\mathrm{p}=0.08)$ for patients with CRC. Unfortunately, RRs were not evaluated in one case and three controls. Median PFS for patients treated in the palliative setting (Figs. 1 and 2) was 4 and 6 months ( $\mathrm{p}=0.8, \mathrm{HR}=1.1$; 95\% CI 0.4-3.0), and median OS 8.4 and 16.4 months ( $\mathrm{p}=0.9$, $\mathrm{HR}=1.4$; 95\% CI 0.3-3.2). Six-month PFS rates were 42 and $50 \%(\mathrm{p}=0.4)$ and 1-year PFS rates were 29 and $33 \%(\mathrm{p}=0.1)$. One-year OS rates were 43 and $58 \%(\mathrm{p}=1.0)$ and 2-year OS rates were 43 and $30 \%(\mathrm{p}=0.5)$. In the adjuvant group (Figs. 3 and 4$)$, there were no significant differences in PFS ( $\mathrm{p}=0.9$, $\mathrm{HR}=1.1 ; 95 \%$ CI $0.2-5.3)$ or $\mathrm{OS}(\mathrm{p}=0.7, \mathrm{HR}=0.7 ; 95 \% \mathrm{CI}$ $0.08-5.3)$. Median times were not reached. For patients treated in adjuvant settings, 1-year PFS rates were 66 and 93\% $(\mathrm{p}=0.6)$ and 3-year PFS rates were 66 and $73 \%(\mathrm{p}=0.7)$. Three-year OS rates were 80 and $80 \%(\mathrm{p}=0.3)$ and 5-year OS rates were 80 and $66 \%(\mathrm{p}=0.4)$. For all patients with SBC and CRC, no significant difference in PFS, recurrence-free survival or OS were observed (data not shown). PFS (Figs. 1 and 3) and OS (Figs. 2 and 4) are shown as cumulated proportions.

According to the multivariates analysis, primary cancer location analyzed as a prognostic factor in SBC vs. CRC patients did not affect PFS ( $\mathrm{p}=0.6, \mathrm{HR}=1.2 ; 95 \%$ CI $0.5-2.8$ ) and $\mathrm{OS}(\mathrm{p}=1.0, \mathrm{HR}=1.0 ; 95 \%$ CI $0.4-2.7)$ (Table IV), or baseline LDH, gender and age (data not shown). Baseline PS $(\mathrm{p}=0.05)$ and tumor stage $(\mathrm{p}=0.001)$ were, however, significant prognostic factors for PFS and OS.

Toxicity and tolerability. No significant differences in cases or controls were noted when the levels of toxicity of the two groups were compared during chemotherapy treatment, except 


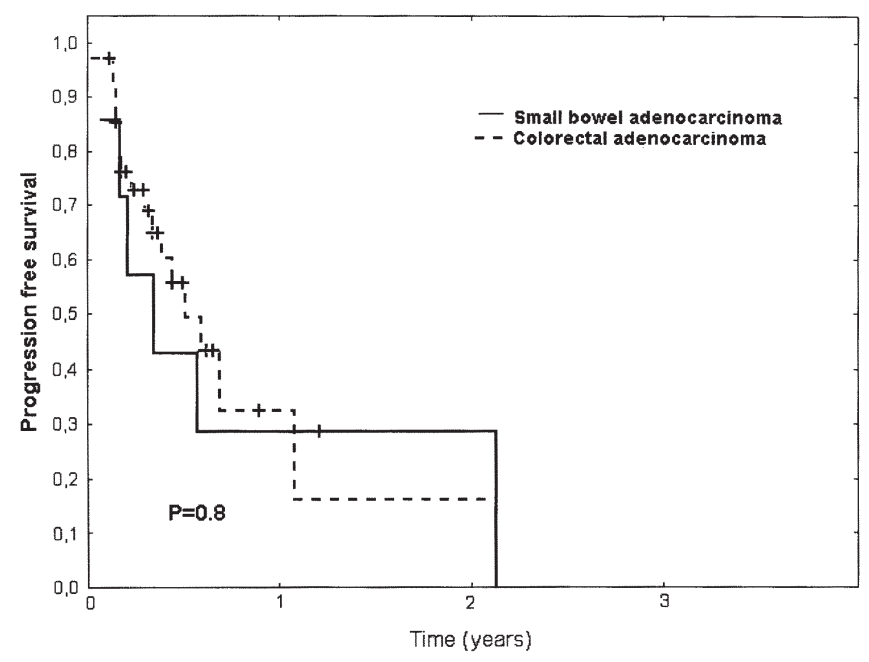

Figure 1. Progression-free survival from start of palliative 5-FU Mayo, capecitabine or Xelox therapy for inoperable small bowel and matched colorectal adenocarcinoma.

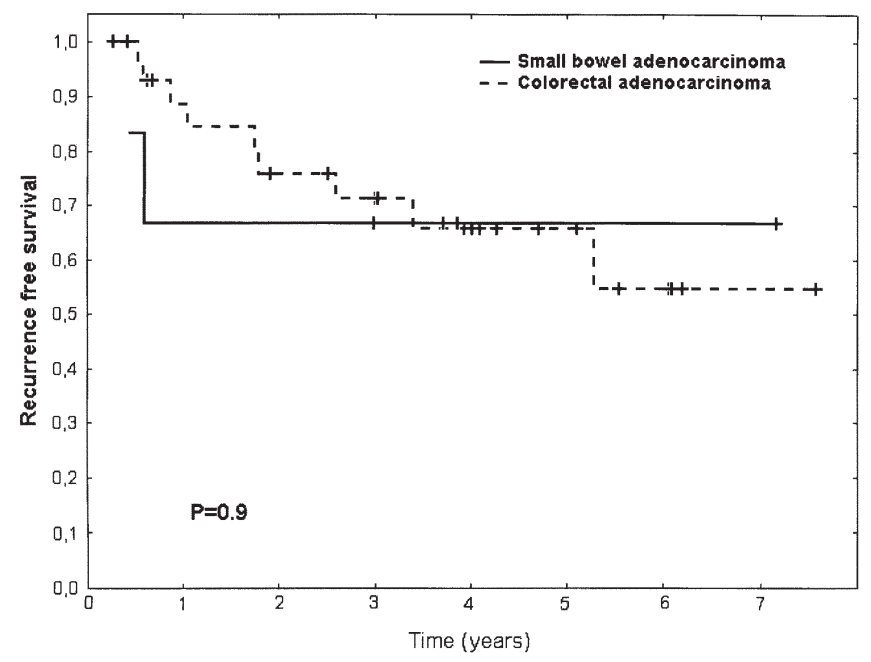

Figure 2. Overall survival from start of palliative 5-FU Mayo, capecitabine or Xelox therapy for inoperable small bowel and matched colorectal adenocarcinoma.

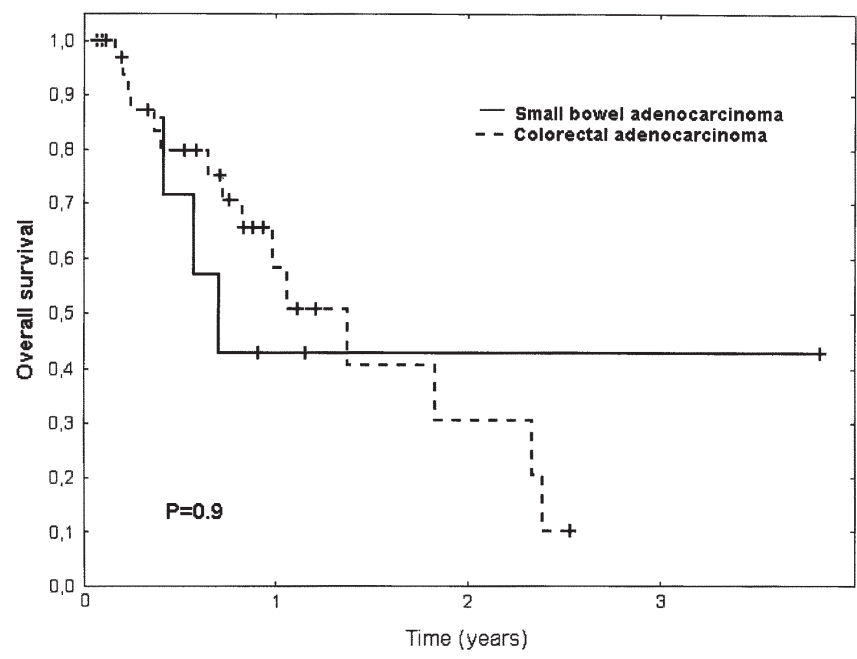

Figure 3. Recurrence-free survival from start of adjuvant 5-FU Mayo chemotherapy following complete resection of small bowel adenocarcinoma and matched colon adenocarcinoma.

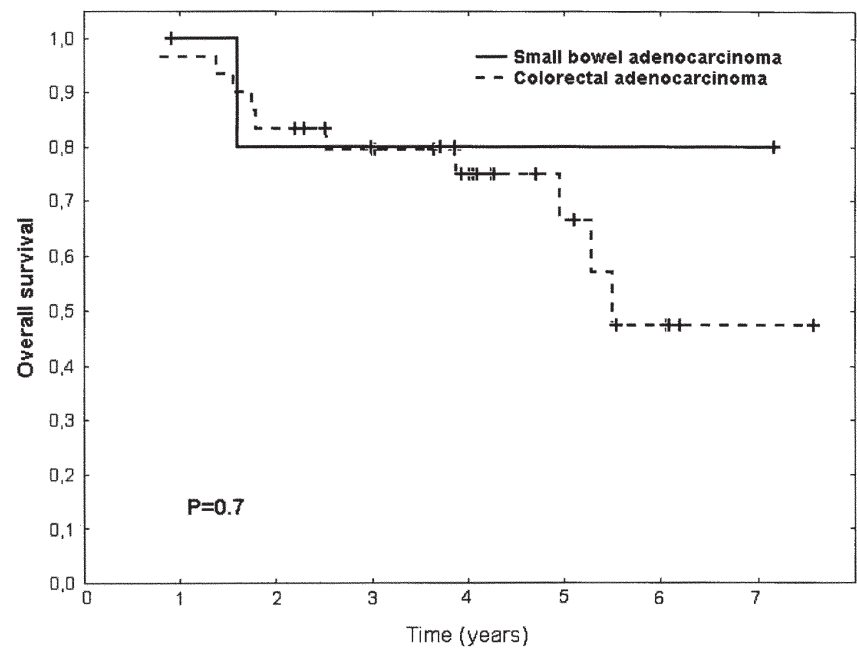

Figure 4. Overall survival from start of adjuvant 5-FU Mayo chemotherapy following complete resection of small bowel adenocarcinoma and matched colon adenocarcinoma.

Table IV. Multivariate analysis (Cox) of progression-free and overall survival for patients with small bowel and colorectal adenocarcinoma.

\begin{tabular}{lccccccc}
\hline & \multicolumn{3}{c}{ Progression-free survival } & & \multicolumn{3}{c}{ Overall survival } \\
\cline { 2 - 3 } & Hazard ratio & $95 \% \mathrm{CI}$ & P-value & & Hazard ratio & 95\% CI & P-value \\
\hline Colorectal/small bowel & 1.2 & $0.5-2.8$ & 0.6 & & 1.0 & $0.4-2.7$ & 1.0 \\
PS baseline & 5.0 & $1.0-25$ & 0.05 & & 3.6 & $0.9-13.5$ & 0.05 \\
Stage & 3.9 & $2.0-7.7$ & 0.001 & & 3.7 & $1.8-7.8$ & 0.001 \\
\hline
\end{tabular}

PS, performance status.

for nausea and vomiting CTC grade 3-4 in the palliative settings ( 14 vs. $3 \%, \mathrm{p}=0.02$, for SBC and CRC patients, respectively). Significant differences in dose reduction were only observed in patients treated with oxaliplatin in the Xelox regimen, who needed a dose reduction in $20 \%$ of SBC cases and $44 \%(p=0.04)$ of CRC cases. Differences in dose 
Table V. Review of the present literature for small bowel cancer patients receiving chemotherapy.

\begin{tabular}{|c|c|c|c|c|}
\hline Author/(Refs.) & $\begin{array}{l}\text { No. of } \\
\text { patients with } \\
\text { adenocarcinoma }\end{array}$ & $\begin{array}{l}\text { No. of patients } \\
\text { receiving } \\
\text { chemotherapy }\end{array}$ & Regimen & $\begin{array}{l}\text { Survival for } \\
\text { patients receiving } \\
\text { chemotherapy }\end{array}$ \\
\hline Jigyasu et al (9) & 14 & 14 & $\begin{array}{l}\text { Palliative: } 5-\mathrm{FU}- \\
\text { based ( } 9 \text { patients) }\end{array}$ & $\begin{array}{l}\text { Median } 9 \text { mo } \\
\text { RR } 7 \%\end{array}$ \\
\hline Ohkusa et al (21) & 1 & 1 & Palliative: UFT & $35 \mathrm{mo}$ \\
\hline $\begin{array}{l}\text { Witham and Harnett } \\
\text { (22) }\end{array}$ & 1 & 1 & $\begin{array}{l}\text { Palliative: } 5-\mathrm{FU} \\
\text { and radiation }\end{array}$ & NA \\
\hline Lambert et al (20) & 28 & 8 & $\begin{array}{l}\text { Adjuvant and palliative: } \\
\text { chemoradiation agent NA }\end{array}$ & NA \\
\hline Onodera et al (23) & 1 & 1 & $\begin{array}{l}\text { Palliative: } 5-\mathrm{FU} \\
\text { and radiation }\end{array}$ & $26 \mathrm{mo}$ \\
\hline Crawley et al (6) & 8 & 8 & $\begin{array}{l}\text { Palliative: 5-FU- } \\
\text { based }\end{array}$ & $\begin{array}{l}\text { Median } 13 \text { mo } \\
\text { RR } 38 \%\end{array}$ \\
\hline Zhou et al (14) & 25 & 27 & $\begin{array}{l}\text { Adjuvant: 5-FU- } \\
\text { based }\end{array}$ & NA \\
\hline Lee et al (24) & 39 & 13 & $\begin{array}{l}\text { Adjuvant: } 5-\mathrm{FU} \\
\text { and radiation }\end{array}$ & NA \\
\hline Mehta et al (25) & 12 & 12 & $\begin{array}{l}\text { Adjuvant: } 5-\mathrm{FU} \\
\text { and radiation }\end{array}$ & Median 34 mo \\
\hline Marchettini et al (26) & 6 & 6 & $\begin{array}{l}\text { Palliative: intraperitoneal } \\
\text { chemotherapy }\end{array}$ & Median 12 mo \\
\hline Talamonti et al (27) & 43 & NA & NA & NA \\
\hline Bettini et al (28) & 3 & $\begin{array}{l}\text { Adjuvant: } 2 \\
\text { Palliative: } 1\end{array}$ & $\begin{array}{l}\text { Adjuvant and palliative: } \\
\text { FOLFOX } 4 \text { or De Gramont }\end{array}$ & NA \\
\hline Morganti et al (29) & 1 & 1 & Palliative chemotherapy & NA \\
\hline Polyzos et al (30) & 3 & 3 & $\begin{array}{l}\text { Palliative: single } \\
\text { agent irinotecan }\end{array}$ & Median 9 mo \\
\hline Gibson et al (7) & 39 & 39 & Palliative: FAM & $\begin{array}{l}\text { Median } 8 \text { mo } \\
\text { RR 18\%; PFS } 5 \text { mo }\end{array}$ \\
\hline Dabaja et al (13) & 217 & $\begin{array}{l}\text { Adjuvant: } 59 \\
\text { Palliative: } 48\end{array}$ & NA & NA \\
\hline Locher et al (10) & 20 & 20 & $\begin{array}{l}\text { Palliative: FUP, ECF, } \\
\text { De Gramont or FOLFOX4 }\end{array}$ & $\begin{array}{l}\text { Median } 35 \text { mo, } 5 \text {-year } \\
\text { survival rates } 38 \%\end{array}$ \\
\hline Sikora et al (31) & 104 & 49 & $\begin{array}{l}\text { Adjuvant: } 5-\mathrm{FU} \\
\text { and radiation }\end{array}$ & $\begin{array}{l}\text { Adjuvant: Median } 22 \text { mo } \\
\text { Palliative: RR } 30 \% \\
\text { Median } 11 \mathrm{mo}\end{array}$ \\
\hline Fishman et al (8) & 113 & $\begin{array}{l}\text { Adjuvant: } 13 \\
\text { Palliative: } 44\end{array}$ & $\begin{array}{l}\text { Adjuvant and } \\
\text { palliative }^{\mathrm{a}}\end{array}$ & \\
\hline
\end{tabular}

NA, not available; RR, response rate; Mo, months; PFS, progression-free survival (median); UFT, tegafur, uracil and mitomycin; FOLFOX4, oxaliplatin, 5-FU and leucovorin; De Gramont, 5-FU and leucovorin; FAM, 5-FU, doxorubicin and mitomycin C; FUP, 5-FU and cosplatin; ECF, epirubicin, cisplatin and 5-FU; ${ }^{5} 5-\mathrm{FU}$, capecitabine, gemcitabine alone or combination with 5-FU or capecitabine, PIE (cisplatin, irinotecan and epirubicin), cisplatin, ECF, taxol and carboplatin, Folfiri (5-FU, FA and irinotecan), Xeleri (capecitabine and irinotecan), irinotecan, FAM, ELF (epirubicin, leucovorin and 5-FU), Folfox. 
reduction in patients treated with 5-FU and capecitabine, or in the number of treatment courses administered, were statistically non-significant.

\section{Discussion}

At the time of this study, experiences with chemotherapy for $\mathrm{SBC}$ are limited. Table $\mathrm{V}$ gives a review of the literature. Between 1950 and 1980 Jigyasu et al reported 14 cases with advanced SBC. All were treated with palliative therapy and different chemotherapy regimens, 9 of which contained 5-FU (9). RRs of 7\% and a median OS of 9 months were reported (9). Crawley et al reported 8 cases with advanced SBC treated with palliative chemotherapy (6) between 1990-1995. All received a 5-FU-based regimen. However all the regimens were different (6). RRs were $37 \%$, PFS was 8 months and the median OS was 13 months (6). In a Phase II trial, Gibson et al evaluated the RRs and OS of 39 SBC patients with advanced disease treated with palliative chemotherapy between 1983-1984 (7). All patients were treated with a regimen combining 5-FU, mitomycin $\mathrm{C}$ and doxorubicin (FAM regimen), which was usually used for gastric cancer patients. RRs were $18 \%$ and the median OS was 8 months (7). Twenty patients, treated in palliative chemotherapy settings with the FUP, ECF, De Gramont or FOLFOX4 regimens, were evaluated by Locher et al, resulting in RRs of $21 \%$, PFS of 8 months and OS of 14 months (10). Fishman et al recently reported on a study evaluating 44 patients with SBC treated palliatively. RRs were $30 \%$ and the median OS was 11 months (8). In summary, the combined results of five studies assessing SBC patients treated with chemotherapy in palliative settings are an OS time of 8-14 months and RRs of 7-37\% (6-10).

As for adjuvant chemotherapy, results from treatment studies are scarce. The studies which have been conducted are few, small and heterogeneous, and have failed to reach firm conclusions. Many of these studies were published one to two decades ago, and were based on a variety of different chemotherapy combinations. To the best of our knowledge, to date only one study has evaluated the survival times of adjuvant chemotherapy following surgery. Fishman et al evaluated 15 SBC patients treated with adjuvant therapy, and found the median OS to be 22 months. In 2004, Dabaja et al evaluated the prognosis for 217 patients with SBC, 59 (27\%) of whom received adjuvant chemotherapy (13). The median OS and 5-year OS times were not evaluated. Based on a Kaplan-Meier survival curve $(\mathrm{p}=0.49)$, the conclusion was that chemotherapy, when combined with surgery (Whipple procedure), had no significant impact on survival times (14). Likewise, in 1999 Zhou et al evaluated 27 patients with different histologic types of SBC who were treated with 5-FUbased adjuvant chemotherapy. However, the median OS and 5-year OS were not reported (14). Based on survival rates (data not shown in article), the conclusion was that adjuvant chemotherapy did not prolong survival times (14).

No prior study has compared the efficacy of chemotherapy on SBC to that of the same chemotherapy applied to the gastrointestinal tumor types for which it was originally developed. Hence, it is not known for sure whether SBC is as responsive to chemotherapy as other gastrointestinal malignancies.
This study evaluates, in a case-control setting, the response of patients with SBC, compared to those with CRC, undergoing palliative capecitabine, the Xelox regimen or adjuvant Mayo treatment. It is one of the first to evaluate capecitabine, Xelox and Mayo regimens for SBC, and the results of the study suggest a lower response rate and worse prognosis for SBC patients than for CRC patients, although the differences did not reach statistical significance. The tendency towards an unfavorable prognosis seems to be more pronounced in palliative settings. However, these results must be viewed while keeping in mind the small number of cases of this rare disease. Controls were obtained from a large database of 581 patients, which enhanced the possibility of a more precise match and minimized the risk of bias. In spite of this, precise matches were not possible. Furthermore, one of the cases was not evaluated for response, which was one of the major endpoints of this study. Unfortunately, these are the terms when investigating a rare disease.

SBC is often diagnosed at an advanced stage because of its presentation with non-specific, insidious symptoms and signs and poor diagnostics possibilities $(2,15,16)$. This results in increased risk of tumor growth and metastasis, which in turn creates a larger tumor burden and higher TNM stage and leads to a worse prognosis. The present study tried to prevent this delay from affecting the results by matching cases and controls according to baseline LDH level and TNM stage. Unfortunately, a precise match was not possible in the adjuvant group based on TNM classification, and so cases and controls were matched according to the more imprecise Dukes' classification instead. In the palliative group, cases and controls were unequally distributed in terms of baseline PS and baseline LDH. This difference in distribution may easily have affected the results because baseline PS, baseline LDH, and $\mathrm{T}$ and $\mathrm{N}$ stage are all important prognostic factors which impact the outcome. These differences, between the characteristics of patients in the case and the control groups, favor a better prognosis for SBC patients than might otherwise be expected. Furthermore, in the palliative group, one case treated with 5-FU (Mayo regimen) was matched to controls treated with capecitabine. When capecitabine is compared to the Mayo regimen in palliative settings with CRC patients, a statistically significant outcome favoring capecitabine is observed in RRs. No difference is observed in PFS and OS (17).

The literature suggests that adenocarcinomas of the duodenum have a worse prognosis than adenocarcinomas of jejunum or ileum $(14,19)$. It is, therefore, noteworthy that in the present study 6 out of 7 patients in the palliative setting, compared to 0 out of 6 patients in the adjuvant setting, had a primary location site in duodenum. This may partly explain why differences in survival times for SBC patients compared to $\mathrm{CRC}$ patients were more pronounced in the palliative than in the adjuvant settings. Furthermore, while the evaluated regimens were effective for SBC patients, they did not achieve a higher RR or OS time than other regimens described in the literature. However, it should be kept in mind that the survival times of the CRC group were also worse than is often reported $(19,20)$. The evaluated regimens for SBC patients in the present study were well tolerated in terms of toxicity.

In conclusion, capecitabine or 5-FU-based chemotherapy for patients with advanced SBC may be less effective, and 
have a less favourable prognosis, than it does for CRC patients. As well, the prognosis for completely resected SBC patients may be worse than it is for CRC patients, though the differences did not reach statistical significance in this small patient sample. Consequently, firm conclusions cannot be drawn because the rarity of the disease hampers large-scale studies. Multicentre studies are warranted in order to confirm or refute these results, and to define the optimal chemotherapy regimes for $\mathrm{SBC}$.

\section{References}

1. Huchin R, Hani AB, Kojodjojo P, Ho R and Snooks SJ: Adenocarcinoma of the small bowel. Anz J Surg 71: 428-437, 2001.

2. Neugot A, Marvin MR, Rella VA and Chabot JA: An overview of adenocarcinoma of the small intestine. Oncology 11: 529-536, 1997.

3. Pfister DG, Benson AB and Somerfield MR: Clinical practice. Surveillance strategies after curative treatment of colorectal cancer. N Engl J Med 350: 2375-2382, 2004.

4. Howe JR, Karnell LH and Scott-Conner C: The American College of Surgeons Commission on Cancer and the American Cancer Society. Adenocarcinoma of the small bowel: review of the National Cancer Data Base, 1985-1995. Cancer 86: 2693-2706, 1999.

5. Delaunoit T, Neczyporenko F, Limburg PJ and Erlichman C: Pathogenesis and risk factors of small bowel adenocarcinoma: a colorectal sibling? Am J Gastroenterol 100: 703-710, 2005.

6. Crawley C, Ross P, Norman A, Hill A and Cunningham D: The Royal Marsden experience of small bowel adenocarcinoma treated with protracred venous infusion 5-fluorouracil. Br J Cancer 78: 508-510, 1998.

7. Gibson MK, Holcroft CA, Kvols LK and Haller D: Phase II study of 5-fluorouracil, doxorubicin, and mitomycin $\mathrm{C}$ for metastatic small bowel adenocarcinoma. Oncologist 10: 132-137, 2005.

8. Fishman PN, Pond GR, Moore MJ, Oza A, Burkes RL, Siu LL, Feld R, Gallinger S, Greig P and Knox JJ: Natural history and effectiveness for advanced adenocarcinoma of the small bowel: a retrospective review of 113 cases. Am J Clin Oncol 29: 225-231, 2006.

9. Jigyasu D, Bedikian AY and Stroehlein JR: Chemotherapy for primary adenocarcinoma of the small bowel. Cancer 53: 23-25, 1984.

10. Locher C, Malka D, Boigé V, Lebray P, Elias D, Lasser P and Ducreux M: Combination chemotherapy in advanced small bowel adenocarcinoma. Oncology 69: 290-294, 2005.

11. Jensen SA, Lønborg JT and Sørensen JB: Benefits and risks of palliative capecitabine based therapy to elderly patients with advanced colorectal cancer; Danish single centre experiences. Acta Oncol 45: 67-76, 2006.

12. Jensen SA, Vilmar A and Sørensen JB: Adjuvant chemotherapy in elderly patients ( $>75$ years) completly resected for colon cancer stage III compared to younger patients: toxicity and prognosis. Med Oncol (In press).
13. Dabaja B, Suki D, Barbara P, Bonnen M and Ajani J: Adenocarcinoma of the small bowel. Cancer 101: 518-526, 2004.

14. Zhou Z, Wan D, Chen G, Chen YB and Pan Z: Primary malignant tumor of the small intestine. World $\mathrm{J}$ Gastroenterol 5: 273-276, 1999.

15. Gill SS, Heumann DM and Mihas AA: Small intestinal neoplasmas. J Clin Gastroenterol 33: 267-282, 2001.

16. Kummar S, Ciesielski TE and Fogarasi MC: Management of small bowel adenocarcinoma. Oncology 16: 1364-1369, 2002.

17. Walko CM and Lindley C: Capecitabine: a review. Clin Ther 27: 23-44, 2005.

18. Lambert P, Minghini A, Pincus W, Kolm P and Perry RR: Treatment and prognosis of primary malignant small bowel tumors. Am Surg 62: 709-715, 1996.

19. Cassidy J, Taberneos J and Twelves C: Xelox (capecitabine plus oxaliplatin): active first-line therapy for patients with metastatic colorectal cancer. Oncology 69: 27-34, 2005.

20. Makatsoris T, Kaloforos HP and Aravantinos G: A Phase II study of capicitabine plus oxaliplatin (Xelox): a new first line option in metastatic colorectal cancer. Int J Gastrointest Cancer 35: 103-109, 2005.

21. Ohkusa T, Ohtomo K, Yamamoto N and Fijimoto H: Primary adenocarcinomas of duodenal bulb benefited by chemotherapy. Dig Dis Sci 36: 1653-1656, 1991.

22. Witham $M$ and Harnett PR: Complete remission and long-term survival with 5-fluorouracil chemotherapy - a case report. Am J Oncol 19: 305-309, 1996.

23. Onodera H, Nishitai R, Shimizu K, Maetani S and Imamura M: Small intestinal cancer with extensive lymph node metastases showing complete remission by methotrexate/5-fluorouracil sequential therapy: report of a case. Surg Today Jpn J Surg 7: 60-63, 1997.

24. Lee J, Whittington R, Williams N, Berry M, Vaughin D, Haller D and Rosato E: Outcome of pancreaticoduodenectomy and impact of adjuvant therapy for ampullary carcinomas. Int J Rad Oncol Biol Phys 47: 945-953, 2000.

25. Mehta VK, Fisher GA, Ford JM, Poen JC, Vierra MA, Oberhelman HA and Bastidas AJ: Adjuvant chemoradiation for 'unfavorable' carcinomas of the ampulla of vater. Arch Surg 136: 65-69, 2001.

26. Marchettini P and Sugarbaker PH: Mucinous adenocarcinomas of the small bowel with peritoneal seeding. Eur J Surg Oncol 28: 19-23, 2002 .

27. Talamonti MS, Goetz LH, Rao S and Joehl RJ: Primary cancer of the small bowel. Arch Surg 137: 564-571, 2002.

28. Bettini AC, Beretta GD, Sironi P, Mosconi S and Labianca R: Chemotherapy in small bowel adenocarcinomas associated with celiac disease: a report of three cases. Tumori 89: 193-195, 2003.

29. Morganti AG, Macchia G, Trodella L, Valentini V, Costamagna G, Mutignani M, Tringali A, Smaniotto D, Luzi S and Cellini N: Complete response after chemoradiation in ampullary carcinoma: a case report. Tumori 89: 82-84, 2003.

30. Polyzos A, Kouraklis G, Giannopoulos, Bramis J, Delladeetsima JK and Sfikakis PP: Irinotecan as salvage chemotherapy for advanced small bowel adenocarcinoma: a series of three patients. J Chemother 15: 503-506, 2003.

31. Sikora SS, Balachandran P and Dimri K: Adjuvant chemoradiation in ampullary cancers. Eur J Surg Oncol 31: 158-163, 2005. 